\title{
Invest in urban youth sexual and reproductive health to achieve a demographic dividend in Africa
}

Joyce Mumah

Jessica Brinton

Carol Mukiira

Caroline W. Kabiru

Chimaraoke O. Izugbara

Follow this and additional works at: https://knowledgecommons.popcouncil.org/departments_sbsr-rh

Part of the Community Health and Preventive Medicine Commons, Demography, Population, and Ecology Commons, Family, Life Course, and Society Commons, International Public Health Commons, Public Health Education and Promotion Commons, and the Women's Health Commons How does access to this work benefit you? Let us know!

\section{Recommended Citation}

Mumah, Joyce, Jessica Brinton, Carol Mukiira, Caroline W. Kabiru, and Chimaraoke O. Izugbara. 2015. "Invest in urban youth sexual and reproductive health to achieve a demographic dividend in Africa," STEP UP Policy Brief. Nairobi: African Population and Health Research Center. 

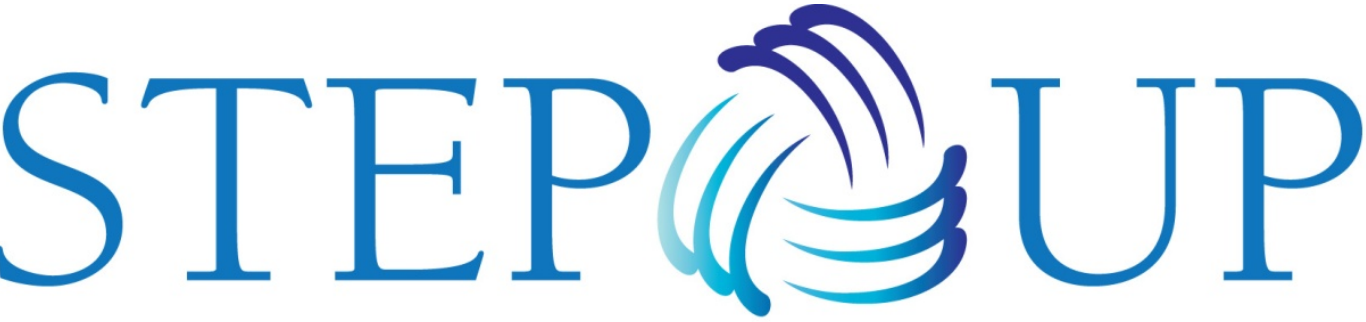

STRENGTHENING EVIDENCE FOR PROGRAMMING ON UNINTENDED PREGNANCY

JUNE 2015

STEP UP generates policy-relevant research to promote an evidencebased approach for improving access to family planning and safe abortion.

We work in Bangladesh, northern India, Ghana, Kenya, and Senegal.

Population Council Coordinating Partner

African Population and Health Research Center

icddr,b

London School of Hygiene and Tropical Medicine

Marie Stopes International

Partners in Population and Development

Funded by

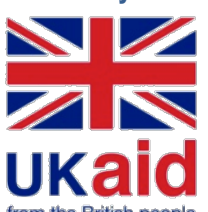

from the British people

\section{INVEST IN URBAN YOUTH SEXUAL AND REPRODUCTIVE HEALTH TO ACHIEVE A DEMOGRAPHIC DIVIDEND IN AFRICA}

\section{Why are youth important?}

Africa's population is the youngest and fastest growing in the world. Young people aged 10-24 years currently constitute about a third of the region's population [1]. The number of youth in the region is expected to grow as fertility rates remain high.

A growing proportion of the urban population are young people born and living in resource-constrained urban slums or who migrate to urban areas in search of opportunities. These urban youth live in an environment that offers limited education and employment opportunities, as well as inadequate housing, health, and social services. The result is an impoverished urban youth population with extremely high rates of unemployment (or underemployment) and low educational attainment.

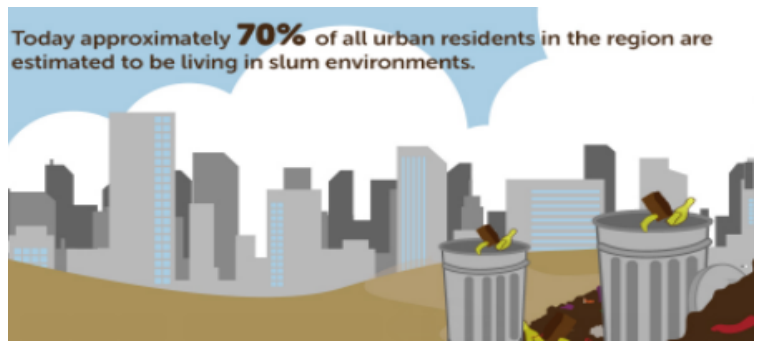

Sexual health challenges of youth in urban African slums

Youth living in slums are at heightened risk for poor sexual and reproductive health (SRH) outcomes including high rates of unintended pregnancies, sexuallytransmitted infections, unsafe abortion, and poor maternal and child health outcomes [2]

Further, girls who have unintended pregnancies are more likely to have limited education [2] with long-term implications for livelihoods and overall wellbeing. For example, a study in Nairobi slums showed that $68 \%$ of adolescent girls between the ages of 12 and 22 years, who had ever been pregnant were out of school [2],

\section{RECOMMENDATIONS}

African governments and Ministries of Health and Education should:

Incorporate economic empowerment programs into urban programming and budget allocation. Poverty is a key hindrance to SRH in poor urban settings. Programs and projects need to help keep youth in school, offer microcredit, train in vocational skills, and offer start-up grants to entrepreneurs

Integrate training on the provision of quality and effective youth-friendly services for health workers. Quality provision of services that meets the critical SRH needs of young people will encourage and increase uptake of services by young people.

Revitalize school health programming to reach inschool youth with culturally relevant, accurate and age appropriate information about sexuality and relationships. 
suggesting that pregnancy during adolescence may signify the end of education for many young girls.

Urban adolescents' heightened SRH risk is driven in part by 1) high levels of poverty which force some adolescents, particularly the most marginalized females, to engage in survival sex; 2) high levels of sexual violence; and 3) limited access to youth-friendly health information and services. Further, although a large proportion of urban adolescents are in school, comprehensive school health programs are not adequately implemented in many countries [3]. For example, only $15 \%$ of schools in Kenya currently implement any form of school health program, with provision of comprehensive sexuality education being even more limited [4].

\section{What is the Demographic Dividend?}

\section{The demographic dividend is window of}

\section{opportunity for accelerated economic growth}

\section{that may result from changes to a country's}

\section{age structure.}

\section{A Comprehensive Solution that Incorporates Economic Empowerment Programming Is Needed}

The future of Africa depends on its ability to harness the potential of its young people. Making the right investments in youth - particularly those in urban areas - can enable the region to experience substantial economic growth and sustainable national development for current and future generations (i.e. capitalizing on the Demographic Dividend).

Successful strategies for addressing the diverse obstacles to urban youth health and well-being must be holistic, addressing not only youth needs for accurate SRH information, but also meeting broader needs like psychosocial and educational support, meaningful parent-child interactions, safe environments, and critical social skills.

The UKaid strategic vision on adolescent girls serves as a good example of a current framework incorporating a comprehensive approach to address the structural drivers of poor SRH outcomes by supporting education, enhancing livelihoods, delaying childbearing and supporting safe delivery, and preventing sexual and gender-based violence.

\section{Suggested citation:}

Mumah, J, Brinton, J, Mukiira, C, Kabiru, CW, Izugbara, C. 2015. "Invest in urban youth sexual and reproductive health to achieve a demographic dividend in Africa" STEP UP Policy Brief, June 2015. Nairobi: African Population and Health Research Center.

\section{"They can set up centers like VCT where you can}

\section{access them without asking for them or somebody}

knowing what you have gone there to do." (Male Youth, Viwandani Slum) [5]

\section{Quality Provision of Youth-Friendly Services Encourages Uptake of SRH Services}

Evidence suggests that young people are hesitant to use SRH services due in part to service provider attitudes regarding adolescent sexual behavior and childbearing. Provider attitude limits the desired range of services accessible to adolescents, who often have to access sources such as shops, which unfortunately do not offer comprehensive SRH packages. A cost effective way to ensure quality youth-friendly services is to improve the clinical aspects of current SRH services to meet the needs of young people through internal re-organization especially through staff training and through outreach services that take the services to young people in and out of school [6].

\section{Revitalizing School Health Programming is Essential}

In sub-Saharan Africa, net primary school attendance ratios are $79 \%$ for males and $75 \%$ for females, while secondary school attendance ratios are $34 \%$ and $32 \%$ for males and females, respectively [7]. These data suggest that schools serve as a critical avenue to reach large numbers of adolescents (especially at early adolescence) with health information and services. Evidence shows that teaching sexual knowledge in schools increases safe sex practices such as delaying sexual debut and young people reporting better communication in their relationship. For in-school youth, evidence points to the need to revitalize school health programing to reach young people in primary and secondary schools, with culturally relevant, accurate and age appropriate information about sexuality and relationships.

\section{CITATIONS AND SUGGESTED READINGS}

1. 2012 Revision of World Population Prospects from the United Nations. Retrieved October 15, 2013 from http://esa.un.org/unpd/wpp/index.htm

2. Beguy D, et al. Status Report on the Sexual and Reproductive Health of Youth Living in Urban Slums in Kenya. 2013, African Population and Health Research Center: Nairobi

3. Strickland B, (2011) First Principles: Designing Effective Education Programs for School Health in Developing Countries. Educational Quality Improvement Program 1 (EQUIP1): American Institutes for Research

4. Republic of Kenya: Accelerating Attainment of Health Goals: The first Kenya Health Sector Strategic and Investment Plan - KHSSP July 2012 - June 2018 Nairobi: Ministry of Medical Services and Ministry of Public Health \& Sanitation 2012

5. Mumah J, et al. (2014) Coping with Unintended Pregnancies: Narratives from Adolescents in Nairobi's Slums. African Population and Health Research Center: Nairobi

6. Erulkar AS, et al. (2005) What Is Youth-Friendly? Adolescents' Preferences for Reproductive Health Services in Kenya and Zimbabwe. African Journal of Reproductive Health

7. United Nations Children's Fund (UNICEF): The State of the World's Children 2014 in Numbers: Revealing Disparities, Advancing Children's Rights. New York, NY: UNICEF; 2014. 